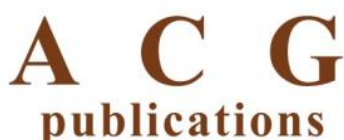

Rec. Nat. Prod. 13:3 (2019) 226-235

records of natural

products

\title{
Bioactivity-Guided Isolation of Anti-Inflammatory Principles from Cistus parviflorus Lam.
}

\author{
Perihan Gürbüz ${ }^{1 *}$, Şengül Dilem Doğan $\odot^{2}$, Gizem Nur Çelik $\odot^{1}$, \\ Hatice Bekci $\odot^{3}$, Ahmet Cumaoğlu $\odot^{4}$, Miyase Gözde Gündüzz $\odot^{5}$ and \\ Mehmet Yavuz Paksoy ${ }^{6}$ \\ ${ }^{1}$ Department of Pharmacognosy, Faculty of Pharmacy, Erciyes University, Kayseri, Türkiye \\ ${ }^{2}$ Department of Basic Sciences, Faculty of Pharmacy, Erciyes University, Kayseri, Türkiye \\ ${ }^{3}$ Department of Food Engineering, Faculty of Engineering, Erciyes University, Kayseri, Türkiye \\ ${ }^{4}$ Department of Biochemistry, Faculty of Pharmacy, Erciyes University, Kayseri, Türkiye \\ ${ }^{5}$ Department of Pharmaceutical Chemistry, Faculty of Pharmacy, Hacettepe University, Ankara, Türkiye \\ ${ }^{6}$ Department of Environmental Engineering, Faculty of Engineering, Munzur University, Tunceli, Türkiye
}

(Received September 07, 2018; Revised October 13, 2018; Accepted October 16, 2018)

\begin{abstract}
Bioactivity-guided fractionation and purification of Cistus parviflorus led to the isolation of two flavan-3-ol derivatives; gallocatechin (1) and epigallocatechin (2) and two flavonoid glycosides; avicularin (3) and trans-tiliroside (4). The structures of the compounds were elucidated on the basis of NMR and ESIMS data. All compounds were isolated from $C$. parviflorus for the first time. Compounds $\mathbf{2}$ and $\mathbf{3}$ exhibited antiinflammatory activity through decreasing the NOS2 and COX2 levels on LPS+IFN- $\gamma$ treated RAW 264.7 cells. Molecular docking studies of avicularin, the most potent compound, were carried out in the active sites of NOS2 and $\mathrm{COX} 2$ to predict the most plausible binding modes and support the experimental data.
\end{abstract}

Keywords: Cistaceae; inflammation; flavonoids; structure elucidation; avicularin; molecular modelling. () 2019 ACG Publications. All rights reserved.

\section{Introduction}

Inflammation is characterized by a series of defense reactions against infection and tissue damage. Inflammation can contribute to the pathogenesis of several disorders including rheumatoid arthritis, osteoarthritis, inflammatory bowel disease and other life-debilitating diseases [1]. Today, many non-steroidal anti-inflammatory drugs (NSAID) are frequently used to treat inflammatory disorders. However, prolonged use of NSAID is related to adverse effects to gastro-intestinal system. Hence, there is a need to develop alternative anti-inflammatory agents that possess minimal side-

* Corresponding author: E-Mail: pgurbuz@erciyes.edu.tr; Phone:090-352-2076666 Fax:090-437-9169 
effects. Development of drugs from natural sources that prevent or inhibit inflammation by downregulating selected inflammatory targets (increased nitric oxide and prostaglandin levels, increased production/activity of inducible nitric oxide synthase (iNOS, NOS2) and cyclo-oxygenase-2 (COX2) etc.) has become of interest in the field of drug development. Cistus (Cistaceae) is the characteristic element of the Mediterranean region and represented with more than 20 species on worldwide [2]. Several Cistus species have extensively been used for the treatment of some ailments, i.e. diarrhea, peptic ulcer, stomachache, high fever, sterility treatment, rheumatism, hemorrhoids, urinary tract infections and diabetes mellitus [3] in folk medicine. There are plenty of pharmacological activity studies on the major representatives of Cistus species mostly conducted on their antiulcerogenic [4], cytotoxic [5] antioxidant and antimicrobial [6] activities. Previous phytochemical studies of various Cistus species led to the isolation of labdane type diterpenes [5] dominantly, flavan-3-ols [7] and flavonoids [8]. In Turkish folk medicine $C$. laurifolius has widespread utilization at inflammationassociated diseases rheumatic pain, high fever and urinary inflammation [9]. In the flora of Turkey, the genus Cistus is represented by five species including C. parviflorus which is naturally growing at west coasts of Turkey [10]. Limited phytochemical and biological activity studies including its essential oil and antimicrobial activities [11] additionally to its phytochemical investigations about 6- $O$ and 8-O methylated flavonoids [12] prompted us to perform the in vitro anti-inflammatory potential of Cistus parviflorus via COX2 and NOS2 inhibition and to isolate the active compound/s through bioactivityguided isolation.

\section{Materials and Methods}

\subsection{General}

NMR (400 MHz for ${ }^{1} \mathrm{H}$ NMR, $100 \mathrm{MHz}$ for ${ }^{13} \mathrm{C}$ NMR) were measured on a Bruker AM 400 spectrometer and MS spectra were obtained on a LC-MS/MS Shimadzu 8040 instrument. Sigel 60 (Merck, 0.063-0.200 mm), was used for open column chromatography. Sephadex LH-20 (SP LH-20) (General Electric's Healthcare) was used for Gel Permeation Chromatography (GPC). LiChroprep RP 18 (Merck, 40-63 $\mu \mathrm{m}$ ) was used for Flash chromatography (Buchi, Switzerland). TLC analyses were carried out on pre-coated Kieselgel $60 \mathrm{~F}_{254}$ aluminum plates (Merck). Compounds were detected by UV fluorescence and spraying $30 \% \mathrm{H}_{2} \mathrm{SO}_{4}$ in $\mathrm{EtOH}$, followed by heating at $100{ }^{\circ} \mathrm{C}$ for $1-2 \mathrm{~min}$.

\subsection{Plant Material}

C. parviflorus Lam. was collected from İzmir-Mordoğan region at about $200 \mathrm{~m}$ altitude in April 2016. A voucher specimen was deposited at the Herbarium of Munzur University under the code PAKSOY 2610.

\subsection{Extraction \& Isolation}

The dried and powdered aerial parts of $C$. parviflorus $(700 \mathrm{~g})$ were extracted with $80 \% \mathrm{MeOH}$ $\left(1 \mathrm{~L} \mathrm{x} \mathrm{3)}\right.$ at $37{ }^{\circ} \mathrm{C}$. After the evaporation of the solvent (yield $\left.10 \%\right)$, the crude $\mathrm{MeOH}$ extract $(70 \mathrm{~g})$ was partitioned between $\mathrm{H}_{2} \mathrm{O}$ and EtOAc. EtOAc (16 g) extract was submitted to column chromatography on Sigel $(2.5 \times 150 \mathrm{~cm})$ and eluted with a gradient system $\mathrm{CHCl}_{3}-\mathrm{MeOH}-\mathrm{H}_{2} \mathrm{O}$ $(80: 20: 2 \rightarrow 61: 32: 7)$. Seven main fractions (FR 1-7) [FR 1: 5.5 g, FR 2: 1.2 g, FR 3: 1.1 g, FR 4: 600 mg, FR 5: $420 \mathrm{mg}$, FR 6: $480 \mathrm{mg}$, FR 7: $700 \mathrm{mg}$ ] were obtained. FR 4 (600 mg) was submitted to SP LH-20 and eluted with Acetone: $\mathrm{MeOH}: \mathrm{H}_{2} \mathrm{O}(2: 1: 1)$ to obtain two subfractions. FR4b (140 mg) was submitted to Sigel column chromatography; eluted with EtOAc-MeOH- $\mathrm{H}_{2} \mathrm{O}$ (100:3:1) solvent system yielding two subfractions. Further purification of FR 1 on RP C18 column $(1.5 \mathrm{~cm} \mathrm{x} 15 \mathrm{~cm})$ and eluted with $\mathrm{H}_{2} \mathrm{O}: \mathrm{MeOH}(100: 0 \rightarrow 50: 50 \%)$ with the MPLC system coupled with a fraction collector (4-5 mbar, $10 \mathrm{~mL} / \mathrm{min})$ to give compounds $1(17 \mathrm{mg})$ and $2(10 \mathrm{mg})$ respectively. FR $2(1.2 \mathrm{~g})$ was fractioned with reverse phase C18 plastic coated glass column $(2.6 \mathrm{~cm} \times 46 \mathrm{~cm})$ and eluted with $\mathrm{H}_{2} \mathrm{O}: \mathrm{MeOH}(100: 0 \rightarrow 0: 100 \%)$ with the MPLC system $(4-5 \mathrm{mbar}, 10 \mathrm{~mL} / \mathrm{min})$ to give compounds 3 $(13 \mathrm{mg})$ and $4(20 \mathrm{mg})$ respectively. 
Gallocatechin (1): Grey powder; Negative ESI/MS m/z: 305 [M-H] ; ${ }^{-1} \mathrm{H}$ NMR (400 MHz, DMSO- $d_{6}$ ): $\delta 9.30(\mathrm{~s}, 1 \mathrm{H}, \mathrm{OH}), 9.08(\mathrm{~s}, 1 \mathrm{H}, \mathrm{OH}), 8.90(\mathrm{~s}, 1 \mathrm{H}, \mathrm{OH}), 8.18(\mathrm{~s}, 1 \mathrm{H}, \mathrm{OH}), 8.11(\mathrm{~s}, 1 \mathrm{H}, \mathrm{OH}), 6.23(\mathrm{~s}$, 2H, H-2'/6'), 5.86 (brs, 1H, H-8), 5.68 (brs, 1H, H-6), 4.93 (brs, 1H, H-2), 4.48-4.35 (m, 1H, H-3),

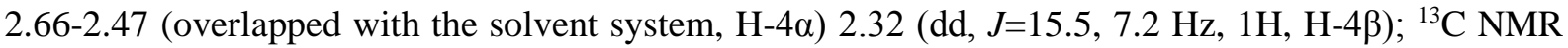
(100 MHz, DMSO- $d_{6}$ ): $\delta 156.8$ (C-7), 156.6 (C-5), 155.6 (C-9), 146.1 (C-3'/C-5'), 132.9 (C-4'), 130.1 (C-1'), 106.3 (C-2'/C-6'), 99.3 (C-10), 95.5 (C-6), 94.1 (C-8), 81.4 (C-2), 66.7 (C-3), 27.8 (C-4)

Epigallocatechin (2): Grey powder; Negative ESI/MS m/z: 305 [M-H] $;{ }^{1} \mathrm{H}$ NMR (400 MHz, DMSO$\left.d_{6}\right) \delta 9.18(\mathrm{~s}, 1 \mathrm{H}, \mathrm{OH}), 8.98(\mathrm{~s}, 1 \mathrm{H}, \mathrm{OH}), 8.76(\mathrm{~s}, 2 \mathrm{H}, \mathrm{OH}), 7.98(\mathrm{~s}, 1 \mathrm{H}, \mathrm{OH}), 6.36\left(\mathrm{~s}, 2 \mathrm{H}, \mathrm{H}-2^{\prime} / 66^{\prime}\right), 5.87$ (d, $J=2.0 \mathrm{~Hz}, 1 \mathrm{H}, \mathrm{H}-8)$ ), 5.70 (d, $J=1.9 \mathrm{~Hz}, 1 \mathrm{H}, \mathrm{H}-6$ ), 4.64 (brs, $1 \mathrm{H}, \mathrm{H}-2), 3.97$ (brd, $J=3.5 \mathrm{~Hz}, 1 \mathrm{H}, \mathrm{H}-$

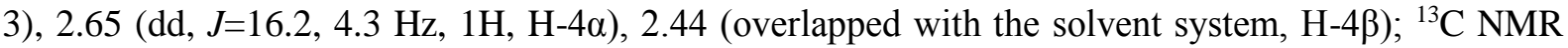
$\left(100 \mathrm{MHz}, \mathrm{DMSO}-d_{6}\right) \delta 156.9$ (C-7), 156.6 (C-5), 156.1 (C-9), 145.7 (C-3'/C-5'), 132.5 (C-4'), 130.1 (C-1'), 106.4 (C-2'/C-6'), 99.1 (C-10), 95.5 (C-6), 94.5 (C-8), 78.5 (C-2), 65.3 (C-3), 28.6 (C-4).

Quercetin 3-O-L-arabinofuranoside (avicularin) (3): Yellow powder; Negative ESI/MS m/z: 433 [M$\mathrm{H}]^{-1}{ }^{1} \mathrm{H}$ NMR (400 MHz, CD $\left.{ }_{3} \mathrm{OD}\right) \delta 7.54\left(\mathrm{~d}, J=2.0 \mathrm{~Hz}, 1 \mathrm{H}, \mathrm{H}-2^{\prime}\right), 7.50$ (dd, $\left.J=8.4,2.1 \mathrm{~Hz}, 1 \mathrm{H}, \mathrm{H}-6^{\prime}\right)$, $6.91(\mathrm{~d}, J=8.4 \mathrm{~Hz}, 1 \mathrm{H}, \mathrm{H}-5$ '), 6.40 (d, $J=2.0 \mathrm{~Hz}, 1 \mathrm{H}, \mathrm{H}-8), 6.22$ (d, $J=2.0 \mathrm{~Hz}, 1 \mathrm{H}, \mathrm{H}-6), 5.48$ (s, $1 \mathrm{H}, \mathrm{H}-$ 1"), 4.35 (brd, $J=2.2 \mathrm{~Hz}, 1 \mathrm{H}, \mathrm{H}-2$ "), 3.94-3.90 (m, 1H, H-3"), 3.90-3.85 (m, 1H, H-4"), 3.51 (dd, $J=3.8,1.9 \mathrm{~Hz}, 2 \mathrm{H}, \mathrm{H}-5 ") ;{ }^{13} \mathrm{C}$ NMR (100 MHz, CD $\left.{ }_{3} \mathrm{OD}\right) \delta 178.5$ (C-4), 164.6 (C-7), 161.6 (C-5), 157.9 (C-2), 157.1 (C-9), 148.4 (C-4'), 144.9 (C-3'), 133.4 (C-3), 121.6 (C-1'), 121.5 (C-6'), 115.4 (C2'), 115.0 (C-5'), 108.0 (C-1"), 104.1 (C-10), 98.4 (C-6), 93.3 (C-8), 86.5 (C-4"), 81.9 (C-2"), 77.2 (C3"), $61.1(\mathrm{C}-5 ")$.

Kaempferol 3-O- $\beta$-(6"-O-trans-p-coumaroyl)-glucopyranoside (trans-tiliroside) (4): Yellow powder; Negative ESI/MS m/z: 593 [M-H] ; ${ }^{1} \mathrm{H}$ NMR (400 MHz, DMSO- $\left.d_{6}\right): \delta 7.97$ (d, $\left.J=8.8 \mathrm{~Hz}, 2 \mathrm{H}, \mathrm{H}-2^{\prime}, 6^{\prime}\right)$, 7.39 (d, $J=16 \mathrm{~Hz}, 1 \mathrm{H}, \mathrm{H}-7$ "') $^{\prime}$, (7.38 (d, $\left.J=8.4 \mathrm{~Hz}, 2 \mathrm{H}, \mathrm{H}-2^{\prime \prime}, 6^{\prime \prime \prime}\right), 6.84$ (d, $\left.J=8.8 \mathrm{~Hz}, 2 \mathrm{H}, \mathrm{H}-3^{\prime}, 5^{\prime}\right), 6.79$ (d, J=8.4 Hz, 2H, H-3"', 5"'), 6.31 (d, J=1.7 Hz, 1H, H-8), 6.10 (brs, 1H, H-6), 6.09 (d, J=16 Hz, 1H, H-8"'), 5.42 (d, J=7.3 Hz, 1H, H-1"), 4.27 (d, $J=10.6 \mathrm{~Hz}, 1 \mathrm{H}, \mathrm{H}-6 " \alpha), 4.02$ (dd, $J=12.0,6.5 \mathrm{~Hz}, 1 \mathrm{H}, \mathrm{H}-$ $6 " \beta), 3.29-3.05$ (m, 4H, remaining sugar signals); ${ }^{13} \mathrm{C}$ NMR (100 MHz, DMSO-d $\left.d_{6}\right) \delta 177.52$ (C-4), 166.66 (C-7), 166.66 (C-9"'), 161.49 (C-5), 160.4 (C-4'), 160.4 (C-4"'), 156.9 (C-2), 156.5 (C-9), 145.1 (C-7"'), 133.3 (C-3), 131.2 (C-2'/C-6'), 130.6 (C-2'"/C-6"'), 125.2 (C-1"'), 121.1 (C-1'), 116.2 (C-3'/C5'), 115.5 (C-3"'/C-5"'), 113.9 (C-8"'), 103.6 (C-10), 101.5 (C-1"), 99.7 (C-6), 94.3 (C-8), 76.6 (C-5"), 74.6 (C-3"), 74.5 (C-2"), 70.3 (C-4"), 63.4 (C-6").<smiles>Oc1cc(O)c2c(c1)O[C@H](c1cc(O)c(O)c(O)c1)[C@H](O)C2</smiles>

1<smiles>O=c1c(OC2OC(CO)C(O)C2O)c(-c2ccc(O)c(O)c2)oc2cc(O)cc(O)c12</smiles>

3<smiles>Oc1cc(O)c2c(c1)O[C@H](c1cc(O)c(O)c(O)c1)[C@H](O)C2</smiles><smiles>O=C(/C=C/c1ccc(O)cc1)OC[C@H]1O[C@@H](Oc2c(-c3ccc(O)cc3)oc3cc(O)cc(O)c3c2=O)C(O)[C@@H](O)C1O</smiles>

Figure 1. Structures of compounds (1-4). 


\subsection{Cell Culture}

Murine macrophage cells (RAW 264.7) from ATCC were grown in Dulbecco's modified Eagle's medium supplemented with $10 \%$ heat-inactivated fetal bovine serum, $100 \mathrm{U} / \mathrm{mL}$ penicillin, and $100 \mu \mathrm{g} / \mathrm{mL}$ streptomycin and $2 \mathrm{mM}$ glutamine at $37^{\circ} \mathrm{C}$ in a humidified incubator with $95 \%$ air and $5 \%$ $\mathrm{CO}_{2}$.

\subsection{Measurement of Cell Viability}

Cell viability was measured based on the 3-(4,5-dimethylthiazol-2-yl)-2,5-diphenyltetrazolium bromide (MTT) assay. 3x10 cells/well were seeded in DMEM. After treatment with EtOAc fractions and pure compounds and culture supernatants were exchanged with medium containing $0.5 \mathrm{mg} / \mathrm{mL}$ MTT for $4 \mathrm{~h}$. The supernatant was removed and $100 \mu \mathrm{L}$ dimethyl sulfoxide added. The absorbance was detected at $570 \mathrm{~nm}$. The value of the control was set at $100 \%$.

\subsection{Quantitative Real-time PCR}

RAW 264.7 cells were cultured in 6 well plate before pretreatment with non-toxic concentration of EtOAc fractions and pure compounds for $24 \mathrm{~h}$. Than cells were treated with LPS+IFN- $\gamma(1 \mu \mathrm{g} / \mathrm{mL}+100 \mathrm{ng} / \mathrm{mL})$ in without phenol red, serum-free medium for $3 \mathrm{~h}$. Total RNA isolated using RNAzol isolation reagent (Sigma-Aldrich, St. Louis, MO), according to the manufacturer's instructions. Total RNA $(1 \mu \mathrm{g})$ was reverse-transcribed to cDNA using a Transcriptor High Fidelity cDNA Synthesis Kit (Roche Diagnostics GmbH, Mannheim, Germany). Real-time PCR was carried out using a Light Cycler 480 System (Roche Diagnostics GmbH, Mannheim, Germany). To quantify cDNA, qPCR was performed using Fast Start Essential DNA probe master mix (Roche Diagnostics $\mathrm{GmbH}$, Mannheim, Germany) and catalogue assay kit (kits consist mix of primers and probes for determination of NOS2, COX2, $\beta$-actin). For each sample, the level of target gene transcripts was normalized to $\beta$-actin.

\subsection{Statistical Analyses}

Statistical analyses between groups for cell viability assay were analyzed with SigmaPlot 12 . statistical software using $\mathrm{t}$ test. $\mathrm{P}$ values $<0.05$ were considered as statistically significant. Fold increase or decrease of mRNA levels was also calculated by REST (relative expression software tool) software developed for group-wise comparison and statistical analysis of relative expression results.

\subsection{Molecular Docking Studies}

The chemical formula of avicularin was built using ChemBiodRAW Ultra 12.0 and saved as Simplified Molecule Input Entry System (SMILES) file. The file was transferred to LigandScout [13] and the structure was geometrically optimized and energy minimized to the 3D structure using the MMFF94x force field. The published crystal structures of NOS2 co-crystallized with AR-C118901 and COX2 co-crystallized with SC-558 were obtained from the Protein Data Bank with the PDB entries 3E6T [14] and 1CX2 [15], respectively. The software GOLD version 5.4 (CCDC, Cambridge, UK) was employed to perform docking [16]. The crystal structure depicted under PDB codes 3E6T and 1CX2 were initially protonated, and water molecules, as well as co-crystallized ligands, were deleted to prepare the enzymes for docking. Default parameters were used and the binding sites were defined within $10 \AA$ around the co-crystallized ligands. The software LidandScout was employed to generate 3D pharmacophore models from the co-crystallized inhibitors inside active pockets of the enzymes. These pharmacophore models were used to rank ten obtained docking poses of avicularin. The most plausible ones were selected based on their abilities to afford the highest amount of chemical interactions described in the 3D pharmacophore model. 


\section{Results and Discussion}

\subsection{Structure Elucidation}

The structures of isolated compounds (Figure 1) were elucidated by 1D- and 2D- NMR analyses and comparison with literature data; gallocatechin (1) [17], epigallocatechin (EGC) (2) [17], avicularin (3) [18], trans-tiliroside (4) [19].

\subsection{Chemotaxonomic Significance}

Unlike the other Cistus species, limited phytochemical studies on $C$. parviflorus led to the isolation and identification of 6- $O$ and 8-O methylated flavonoids [12]. The present study reports on the isolation and structure elucidation of four known compounds from the aerial parts of $C$. parviflorus. To our knowledge this is the first report of compounds 1-4 from C. parviflorus and compound $\mathbf{3}$ from genus Cistus. Plenty of phytochemical studies revealed that polyphenolic compounds; particularly flavan-3-ols, flavonols, flavonoid glycosides and acyl-glycosyl flavonoids are the characteristic and predominant elements of relatively polar fractions of Cistus species [7, 20]. In a former study on C. salviifolius, the arabinopyranoside derivative of quercetin was isolated [19] from a Cistus specie for the first time and beside this in the present study; avicularin a arabinofuranoside derivative of quercetin, was also isolated and characterized from C. parviflorus as well as from family Cistaceae for the first time. The presence of this diverse glycosylation pattern in Cistus species definitely enriches the chemical diversity and provides evidence for the chemotaxonomic studies of the genus Cistus and the family Cistaceae as well.

\subsection{Cell viability and Quantitative Real-time PCR}

Cytotoxicity of $C$. parviflorus methanol extract (CPME), its fractions and pure compounds were tested with MTT assay. RAW 264.7 macrophage cells were pretreated with increasing concentration $(6.25,12.5,25,50,100,200 \mu \mathrm{g} / \mathrm{mL})$ of CPME and the fractions of this extract for 24h. CPME was cytotoxic over $25 \mu \mathrm{g} / \mathrm{mL}$ and FR 1, FR 2, FR 3, FR 4, FR 5, FR 6 and FR 7 were toxic over 12.5, 200, 200, 12.5, 100, 200 and $200 \mu \mathrm{g} / \mathrm{mL}$ respectively. Non-toxic highest concentration of extract and fractions were selected and used in the subsequent experiments for testing their protective effect on LPS+IFN- $\gamma$ induced inflammatory response. Additionally, we tried to find the non-toxic highest concentration of compounds (isolated from FR 2 and FR 4; gallocatechin, epigallocatechin, avicularin and trans-tiliroside). RAW 264.7 macrophage cells were pretreated with increasing concentration $(5,10,20,40,80 \mu \mathrm{M})$ of gallocatechin, epigallocatechin, avicularin and trans-tiliroside for $24 \mathrm{~h}$. According to the cytotoxicity results gallocatechin, epigallocatechin and trans-tiliroside were not toxic in any doses used whereas avicularin was toxic over $20 \mu \mathrm{M}$. Thus, for testing their protective effect on LPS+IFN- $\gamma$ induced inflammatory response these nontoxic doses; $20 \mu \mathrm{M}$ avicularin and 80 $\mu \mathrm{M}$ of gallocatechin, epigallocatechin and trans-tiliroside were used. Protective role of CPME, its fractions and purified compounds were tested against LPS+IFN- $\gamma$ induced inflammatory response. Treatment with LPS+IFN- $\gamma$ caused significantly upregulation of NOS2 and COX2 mRNA levels 9.71 fold and 5.69 fold respectively (data not shown on figures). However, pretreatment with highest nontoxic concentration of $C$. parviflorus methanol extract, FR 2 and FR 4 were alleviated proinflammatory effect of LPS+IFN- $\gamma$ by decreasing both NOS2 and COX2 mRNA levels (Figure 2). 


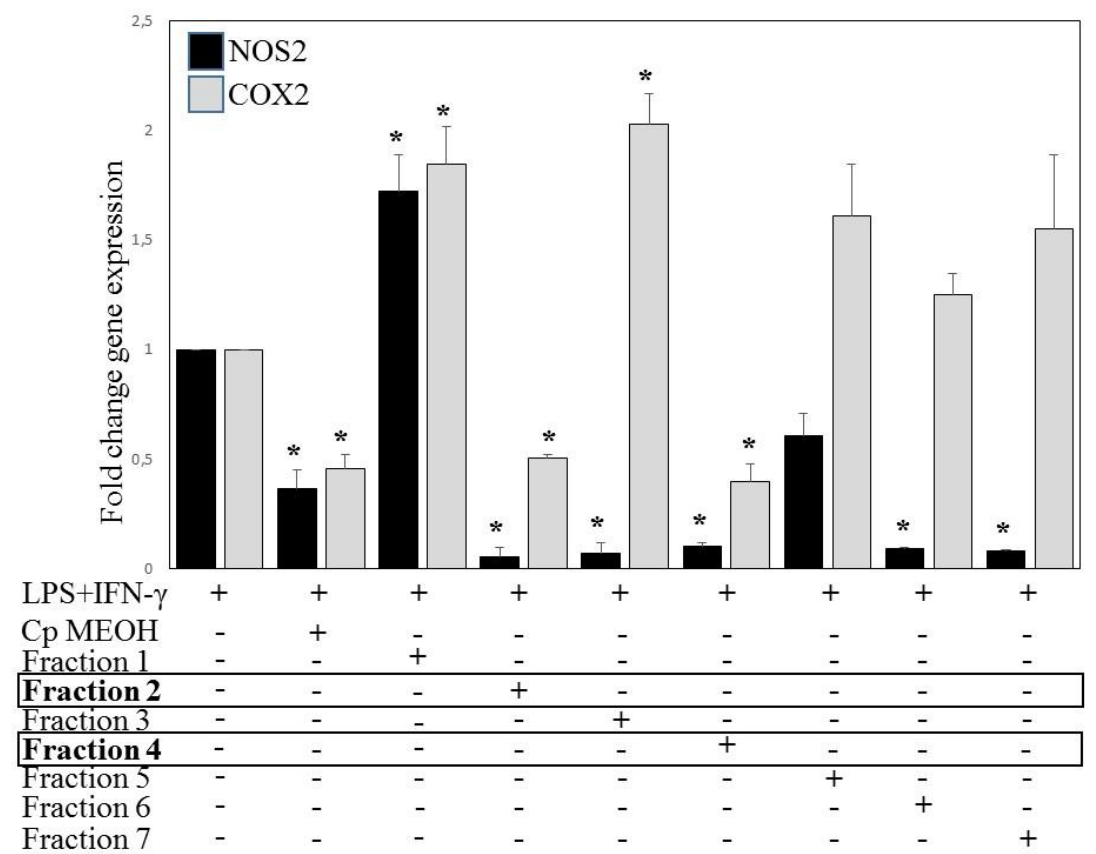

Figure 2. Effects of C. parviflorus methanol extract and its fractions on proinflammatory genes NOS2 and COX2 in RAW 264.7 macrophage cells. Following pretreatment with $C$. parviflorus methanol extract $(25 \mu \mathrm{g} / \mathrm{mL})$ and FR $1(12.5 \mu \mathrm{g} / \mathrm{mL})$, FR $2(200 \mu \mathrm{g} / \mathrm{mL})$ FR $3(200 \mu \mathrm{g} / \mathrm{mL})$, FR $4(12.5 \mu \mathrm{g} / \mathrm{mL})$ FR $5(100)$, FR $6(200 \mu \mathrm{g} / \mathrm{mL})$ and FR $7(200 \mu \mathrm{g} / \mathrm{mL})$ for $3 \mathrm{~h}$, cells were treated with LPS+IFN- $\gamma(1$ $\mu \mathrm{g} / \mathrm{mL}+100 \mathrm{ng} / \mathrm{mL})$ for $3 \mathrm{~h} . \mathrm{n}=3, * \mathrm{p}<0.05 \mathrm{vs}$. LPS+IFN- $\gamma$.

In addition to all these results, when we compare with only LPS+IFN- $\gamma$ treatment, pretreatment with epigallocatechin and avicularin caused a significant decrease in both NOS2 and COX2 mRNA levels. Furthermore, pretreatment with gallocatechin and trans-tiliroside decreased NOS2 and COX2 levels, but the differences in COX2 levels did not reach any statistically significance (Figure 3).

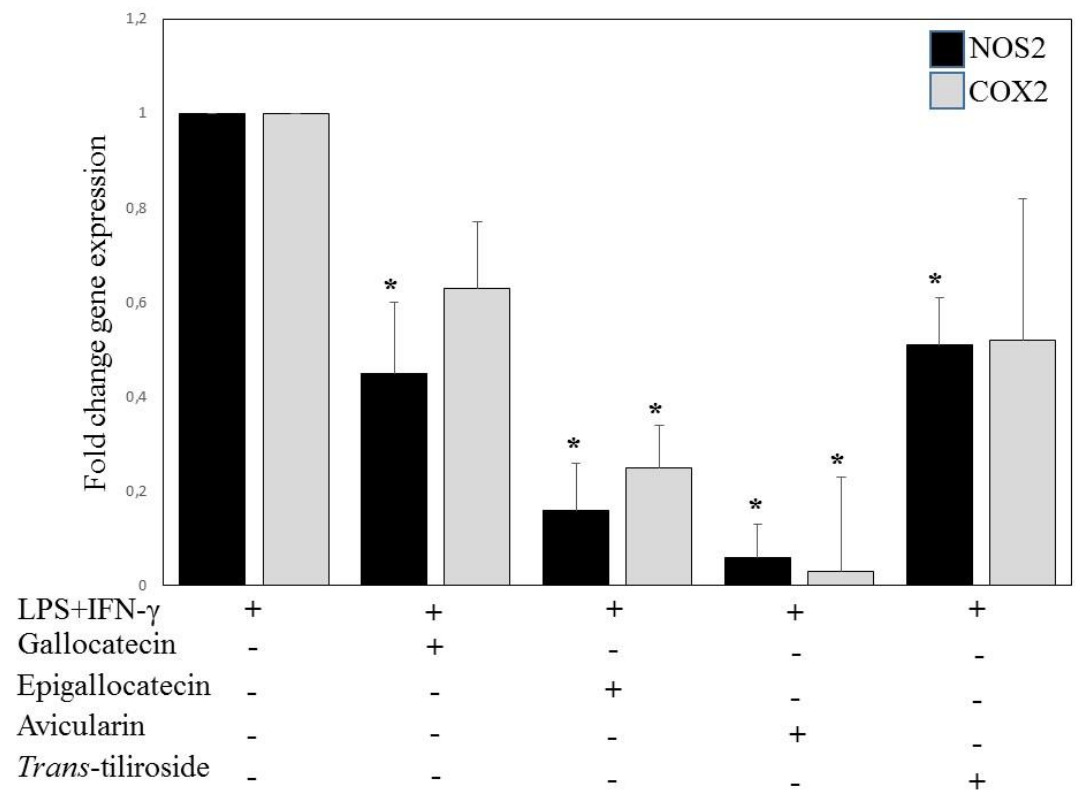

Figure 3. Effects of gallocatechin, epigallocatechin, avicularin and trans-tiliroside on proinflammatory genes NOS2 and COX2 in RAW 264.7 macrophage cells. Following pretreatment with gallocatechin $(80 \mu \mathrm{M})$, epigallocatechin $(80 \mu \mathrm{M})$, avicularin $(20 \mu \mathrm{M})$ and trans-tiliroside $(80$ $\mu \mathrm{M})$ for $3 \mathrm{~h}$, cells were treated with LPS+IFN $-\gamma(1 \mu \mathrm{g} / \mathrm{mL}+100 \mathrm{ng} / \mathrm{mL})$ for $3 \mathrm{~h} . \mathrm{n}=3, * \mathrm{p}<0.05 \mathrm{vs}$. LPS+IFN- $\gamma$. 
In previous studies anti-inflammatory activities of Cistus laurifolius were demonstrated through different in vitro and in vivo models such as prostaglandin inhibition [21] carrageenaninduced hind paw edema model, acetic acid-induced, increased vascular permeability model [22]. Also methanol extract of Cistus laurifolius leaves, as well as various fractions obtained from this crude extract, were shown to inhibit inflammatory cytokines (IL-1, IL-1 $\beta$ and TNF- $\alpha$ ), which also support the traditional utilization of Cistus laurifolius [23]. For instance, the anti-inflammatory and analgesic effects of Cistus ladaniferus aqueous extract have demonstrated experimentally in rats [24]. Potent anti-inflammatory activity of different class of flavonoids including flavonol and flavanol derivatives was reported previously [25]. Plenty of different studies on one of the major green tea polyphenol epigallocatechin gallate (EGCG), quercetin and kaempferol has shown to possess anti-inflammatory activities via COX2 and NOS2 inhibition [26-28] in various studies. Avicularin, a quercetin derivative exhibits anti-inflammatory activity such as suppression of $\mathrm{NO}$ and $\mathrm{PGE}_{2}$ production and cytokine release by presumably inhibiting nuclear translocation of NF-kB in LPS-stimulated RAW 264.7 macrophage cells [29]. In another study, pretreatment with avicularin isolated from Polygonum aviculare decreased TNF- $\alpha$ protein expression in $\mathrm{H}_{2} \mathrm{O}_{2}$ induced neuronal cells [30]. Other isolated flavan derivative EGC decreased proinflammatory cytokines (IL-6, TNF-a) and NO levels in LPS stimulated neutrophils via suppressing the activation of TLR-4/NFkB p65 signal pathway [31]. Our results indicate that crude $\mathrm{MeOH}$ extract, FR 2, FR 4, compounds 2 and 3 obtained from FR 2 and FR 4 were shown to potently suppress NOS2 and COX2 levels in LPS+IFN- $\gamma$-activated RAW 264.7 cells.

\subsection{Molecular Docking Studies}

Among the isolated compounds, avicularin was screened at the lowest concentration and found to be the most potent anti-inflammatory agent. Therefore, molecular docking studies were carried out to gain insights into the interactions of this compound within the binding pockets of the studied enzymes.

Best docking pose of avicularin in the active site of NOS2 revealed that the compound is oriented in the pocket lined by heme in the same manner as the co-crystallized ligand. Only 3,4dihydroxyphenyl ring slightly orients outside the binding pocket, but this moiety forms hydrophobic interactions with TRP457. The interactions of avicularin in the NOS2 active-site heme pocket involve hydrogen bonds to GLN257, TYR341, GLU371, ASP376, ARG382 via the hydroxyl groups to stabilize the ligand. Dihydroxychromene ring is almost parallel to the heme plane, and this results in an additional hydrogen bond (Figure 4). These findings are consistent with the critical residues involved in inhibitor binding reported in the literature for highly potent inhibitors [14].
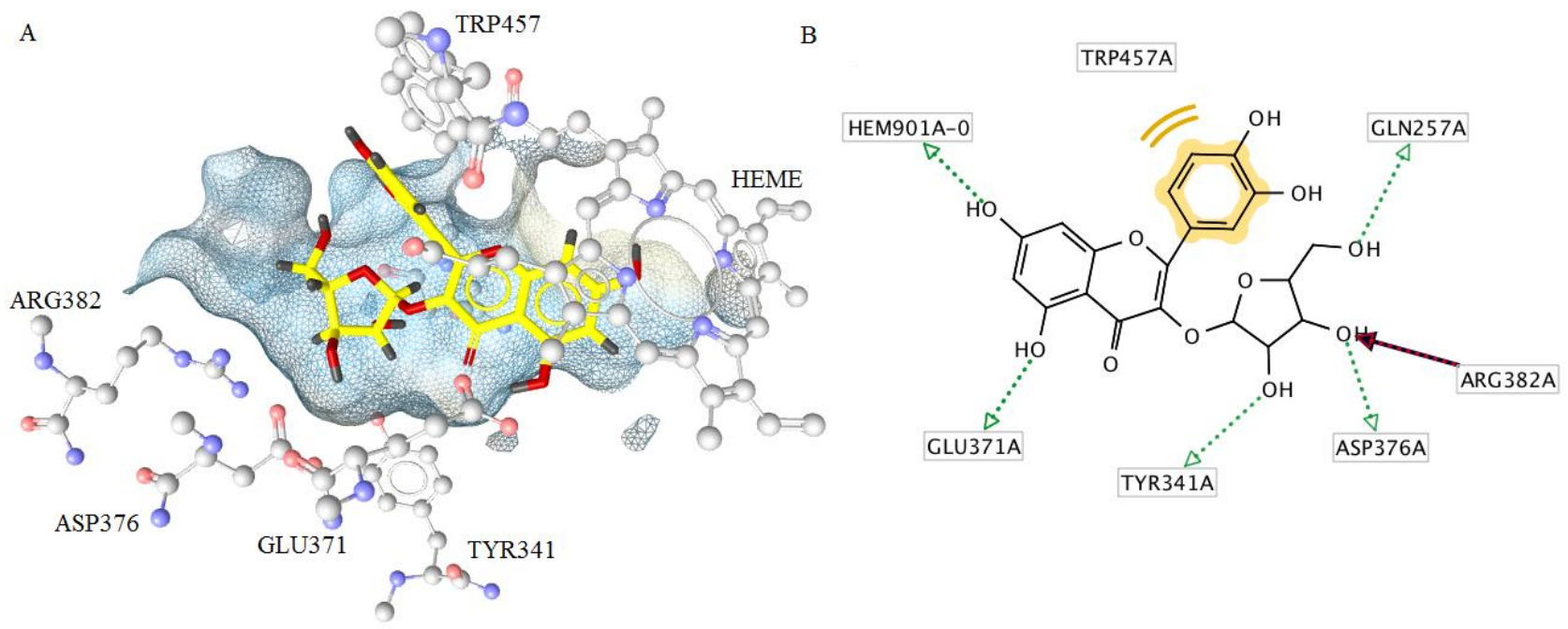

Figure 4. Identified interaction patterns of avicularin after docking into NOS2 active site in 3D-(A) 
and 2D-(B) representation. Pharmacophoric features are visualized as green arrows (hydrogen bond donor), red arrow (hydrogen bond acceptor), and yellow sphere (hydrophobic interaction).

Binding conformation of avicularin in the active pocket of COX2 overlaid with the original co-crystallized ligand, and the pharmacophore features and 2D interactions of avicularin within the binding site of the enzyme are shown in Figure 5. The hydrophobic pocket formed by the residues LEU352, TYR355, PHE518, VAL523 and SER353 hosts the 3,4-dihydroxyphenyl ring and this results in hydrophobic interactions with VAL523 and TYR355. The hydroxyl substituent at the C-4 position of the mentioned ring is responsible for interacting with the enzyme via forming a hydrogen bond with HIS90. The oxolane and chromene rings of avicularin occupy the other two hydrophobic cavities whereas the interactions of avicularin with these pockets involve two hydrogen bonds to MET522 and ALA527. Additionally, the chromene ring interacts with ARG120.
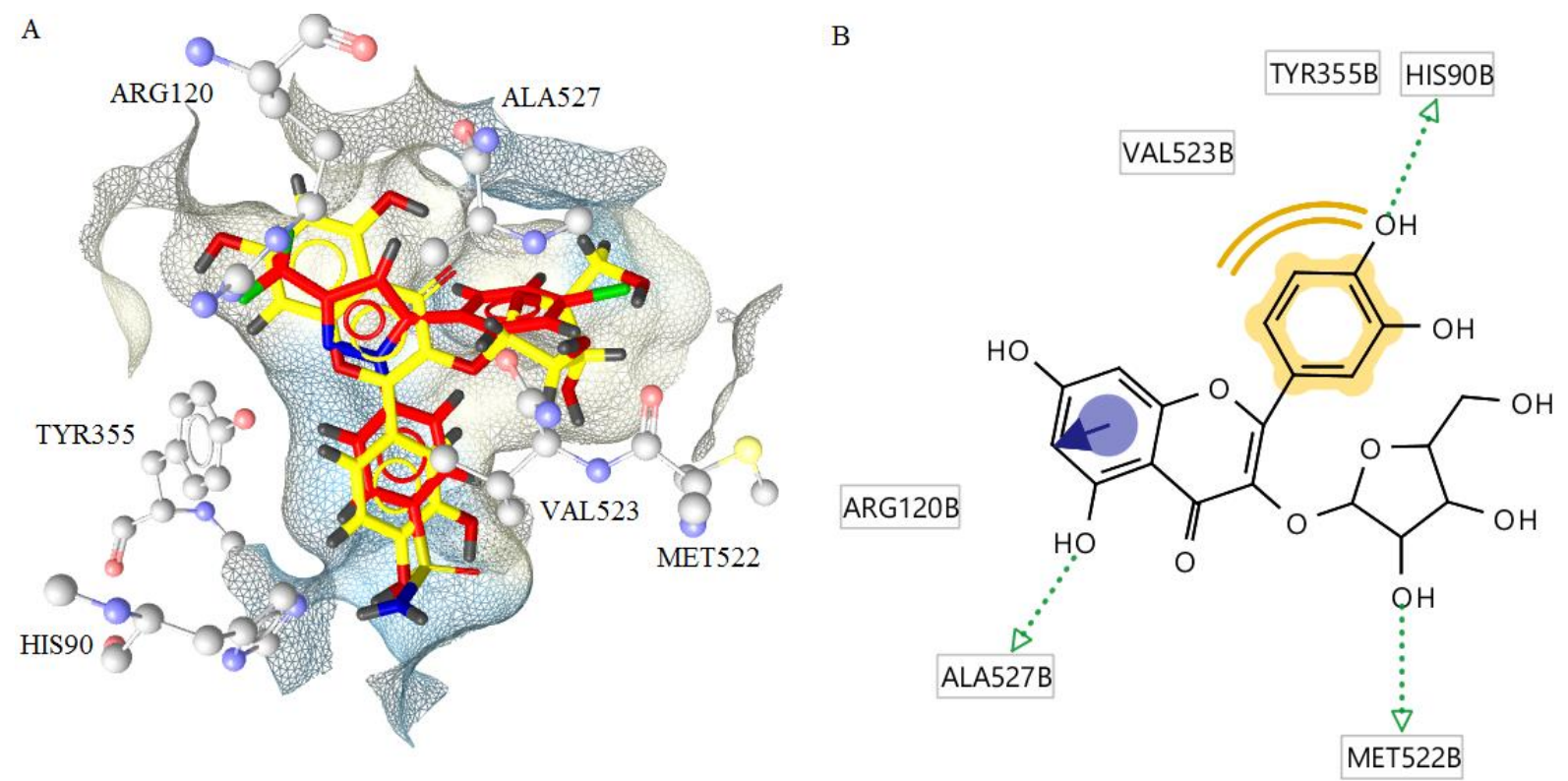

Figure 5. Overlay of the co-crystallized ligand (red; based on the PDB entry 1CX2) with the topranked docked binding pose of avicularin (yellow) at the active site of COX2 (A) and 2Drepresentations of the pharmacophores (B). Pharmacophoric features are represented as green arrow (hydrogen bond donor), yellow sphere (hydrophobic interaction), and blue ring (aromatic ring).

In conclusion, the inhibition of NOS2 and COX2 levels by those flavonoids could be an important contributing factor to their anti-inflammatory and immune regulatory activities along with the traditional use of Cistus species.

\section{Acknowledgments}

The authors are indebted to the Research Foundation of Erciyes University (Project Number: THD-2017-7810) for their financial support of this work.

\section{ORCID}

Perihan Gürbüz: 0000-0002-3056- 411X

Şengül Dilem Doğan: 0000-0003-1761-188X

Gizem Nur Çelik: 0000-0001-8542-1223

Hatice Bekci: 0000-0003-3268-709X

Ahmet Cumaoğlu: 0000-0002-3997-7746

Miyase Gözde Gündüz: 0000-0002-2287-9509

Mehmet Yavuz Paksoy: 0000-0001-9581-4514 


\section{References}

[1] P.J. Barnes and M. Karin (1997). Nuclear factor $\kappa \mathrm{B}$, a pivotal transcription factor in chronic inflammatory diseases, N. Engl. J. Med. 336, 1066-1071.

[2] T.P. List. http://www.theplantlist.org. 2013 1st January]; Version 1.1.:[

[3] T. Baytop (1999). Türkiye'de Bitkiler İle Tedavi (Geçmişte ve Bugün). İstanbul Üniversitesi Eczacılık Fakültesi, İstanbul.

[4] E. Yeşilada, I.1. Gürbüz and H. Shibata (1999). Screening of turkish anti-ulcerogenic folk remedies for anti-Helicobacter pylori activity, J. Ethnopharmacol. 66, 289-293.

[5] C. Demetzos, K. Dimas, S. Hatziantoniou, T. Anastasaki and D. Angelopoulou (2001). Cytotoxic and anti-inflammatory activity of labdane and cis-clerodane type diterpenes, Planta Med. 67, 614-618.

[6] A. Güvenç, S. Yıldız, A.M. Özkan, C.S. Erdurak, M. Coşkun, G. Yılmaz, T. Okuyama and Y. Okada (2005). Antimicrobiological studies on Turkish Cistus. species, Pharm. Biol. 43, 178-183.

[7] F. Qa'dan, F. Petereit, K. Mansoor and A. Nahrstedt (2006). Antioxidant oligomeric proanthocyanidins from Cistus salvifolius, Nat. Prod. Res. 20, 1216-1224.

[8] T. Vogt, P. Proksch and P.-G. Gülz (1987). Epicuticular flavonoid aglycones in the genus Cistus, Cistaceae, J. Plant. Physiol. 131, 25-36.

[9] E. Yeşilada, Honda, G. Sezik, E. Tabata, M. Fujita, T. Tanaka, T. Takeda and Y. Takaishi, (1995). Traditional medicine in Turkey. V. Folk medicine in the inner Taurus Mountains, J. Ethnopharmacol. 46, 133-152.

[10] M.J.E. Coode (1988). Cistaceae, in: Flora of Turkey and the East Aegean Islands.,ed: P. Davis, Mill, R., Tan, K., Edinburgh University Press, Edinburgh, pp. 61.

[11] M. Öğ̈̈tveren and S.S. Tetik (2004). Composition of the essential oil of Cistus parviflorus L. from Turkey, J. Essent. Oil Res., 16, 115-116.

[12] T. Vogt, P. Proksch, P.-G. Gülz and E. Wollenweber (1987). Rare 6-and 8-O-methylated epicuticular flavonols from two Cistus species, Phytochemistry 26, 1027-1030.

[13] G. Wolber and T. Langer (2005). LigandScout: 3-D pharmacophores derived from protein-bound ligands and their use as virtual screening filters, J. Chem. Inform. Model. 45, 160-169.

[14] E.D. Garcin, A.S. Arvai, R.J. Rosenfeld, M.D. Kroeger, B.R. Crane, G. Andersson, G. Andrews, P.J. Hamley, P.R. Mallinder and D.J. Nicholls (2008). Anchored plasticity opens doors for selective inhibitor design in nitric oxide synthase, Nat. Chem. Biol. 4, 700-707.

[15] R.G. Kurumbail, A.M. Stevens, J.K. Gierse, J.J. McDonald, R.A. Stegeman, J.Y. Pak, D. Gildehaus, T.D. Penning, K. Seibert and P.C. Isakson (1996). Structural basis for selective inhibition of cyclooxygenase-2 by anti-inflammatory agents, Nature, 384, 644-648.

[16] G. Jones, P. Willett, R.C. Glen, A.R. Leach and R. Taylor (1997). Development and validation of a genetic algorithm for flexible docking, J. Mol. Biol. 267, 727-748.

[17] A.L. Davis, Y. Cai, A.P. Davies and J. Lewis (1996). ${ }^{1} \mathrm{H}$ and $1{ }^{3} \mathrm{C}$ NMR assignments of some green tea polyphenols, Magn. Reson. Chem. 34, 887-890.

[18] X. Zhang, P.T. Thuong, W. Jin, N.D. Su, K. Bae and S.S. Kang (2005). Antioxidant activity of anthraquinones and flavonoids from flower of Reynoutria sachalinensis, Arch. Pharm. Res. 28, 22-27.

[19] P. Gürbüz, L.Ö. Demirezer, Z. Güvenalp, A. Kuruüzüm-Uz and C. Kazaz (2015). Isolation and structure elucidation of uncommon secondary metabolites from Cistus salviifolius L, Rec. Nat. Prod. 9, 175.

[20] E. Saracini, M. Tattini, M. Traversi, F. Vincieri and P. Pinelli (2005). Simultaneous LC-DAD and LCMS determination of ellagitannins, flavonoid glycosides, and acyl-glycosyl flavonoids in Cistus salvifolius L. leaves, Chromatographia 62, 245-249.

[21] S.K. Sadhu, E. Okuyama, H. Fujimoto, M. Ishibashi and E. Yesilada (2006). Prostaglandin inhibitory and antioxidant components of Cistus laurifolius, a Turkish medicinal plant, J. Ethnopharmacol. 108, 371-378.

[22] E. Küpeli and E. Yesilada (2007). Flavonoids with anti-inflammatory and antinociceptive activity from Cistus laurifolius L. leaves through bioassay-guided procedures, J. Ethnopharmacol.112, 524-530.

[23] E. Yeşilada, O. Üstün, E. Sezik, Y. Takaishi, Y. Ono and G. Honda (1997). Inhibitory effects of Turkish folk remedies on inflammatory cytokines: interleukin-1 $\alpha$, interleukin-1 $\beta$ and tumor necrosis factor $\alpha$, J. Ethnopharmacol. 58, 59-73.

[24] A.E.H. El Youbi, L. El Mansouri, S. Boukhira, A. Daoudi and D. Bousta (2016). In vivo antiinflammatory and analgesic effects of aqueous extract of Cistus ladanifer L. from morocco, Am. J. Ther. 23, 1554-1559. 
[25] G. Toker, E. Küpeli, M. Memisoğlu and E. Yesilada (2004). Flavonoids with antinociceptive and antiinflammatory activities from the leaves of Tilia argentea (silver linden), J. Ethnopharmacol. 95, 393397.

[26] V. García-Mediavilla, I. Crespo, P.S. Collado, A. Esteller, S. Sánchez-Campos, M.J. Tuñón and J. González-Gallego (2007). The anti-inflammatory flavones quercetin and kaempferol cause inhibition of inducible nitric oxide synthase, cyclooxygenase-2 and reactive C-protein, and down-regulation of the nuclear factor kappaB pathway in Chang Liver cells, Eur. J. Pharm. Biol. 557, 221-229.

[27] T. Hussain, S. Gupta, V.M. Adhami and H. Mukhtar (2005). Green tea constituent epigallocatechin-3gallate selectively inhibits COX- 2 without affecting COX- 1 expression in human prostate carcinoma cells, Int. J. Cancer 113, 660-669.

[28] K.A. O’Leary, S. de Pascual-Tereasa, P.W. Needs, Y.-P. Bao, N.M. O’Brien and G. Williamson (2004). Effect of flavonoids and vitamin E on cyclooxygenase-2 (COX-2) transcription, Mut. Res. 551, 245 254.

[29] J.-W.L. Van Anh Vo, J.-E. Chang, J.-Y. Kim, N.-H. Kim, H.J. Lee, S.-S. Kim, W. Chun and Y.-S. Kwon (2012). Avicularin inhibits lipopolysaccharide-induced inflammatory response by suppressing ERK phosphorylation in RAW 264.7 macrophages, Biomol. Ther. 20, 532.

[30] S.H. Park, S. Jang, E. Son, S.W. Lee, S.D. Park, Y.-Y. Sung and H.K. Kim (2018). Polygonum aviculare L. extract reduces fatigue by inhibiting neuroinflammation in restraint-stressed mice, Phytomedicine 42, 180-189.

[31] M. Marinovic, A. Morandi and R. Otton (2015). Green tea catechins alone or in combination alter functional parameters of human neutrophils via suppressing the activation of TLR-4/NFאB p65 signal pathway, Toxicol. in Vitro, 29, 1766-1778.

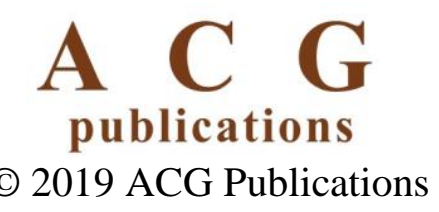

